\title{
Developing a methodology for public engagement with critical research
}

Policy Futures in Education $0(0) 1-15$

(C) The Author(s) 2017 Reprints and permissions: sagepub.co.uk/journalsPermissions.nav DOI: $10.1|77 /| 47821031773952 \mid$ journals.sagepub.com/home/pfe

\section{Ruth Boyask (D)}

Auckland University of Technology, New Zealand

\section{Katy Vigurs}

University of Derby, UK

\begin{abstract}
In this article we argue that a refined understanding of 'public' and 'public engagement' can help researchers who produce critical research make better decisions towards achieving policy influence. We acknowledge the challenges critical researchers face in putting their research to work within the public domain. Critical research struggles to gain influence in bounded public spheres where research is valued as a consumable commodity rather than for its integrity or capacity for informing change. A starting point for developing a method of engagement is to understand better 'publics' and the different ways they may be conceptualised. We draw on a framework of three conceptualisations of the public in public engagement: bounded, normative and emergent. We use this framework to analyse our own experience of public engagement and attempts at policy influence in the Respecting Children and Young People Project. Through this analysis we recognise alternative ways to conceive of publics that may direct us away from some courses of action, and open new possibilities for public engagement with critical research.
\end{abstract}

\section{Keywords}

Research utilisation, policy influence, impact, critical research, public engagement 
For the reasons already outlined by other papers in this special issue, it is difficult for researchers to overcome the challenges of putting critically informed educational research to work on issues of public policy. Our networks of influence tend to be far removed from governmental power, our critiques of the social status quo and its oppressive inequalities do not sit comfortably with neo-liberal state agendas and the knowledge we produce has a lesser exchange value in the transaction between research and policy. We work in institutional contexts where we as researchers are increasingly evaluated on the utility or impact of our work, yet the majority of research judged as impactful is condensed within elite universities, underpinned by a small group of normative methodologies and associated with narrowly construed and high-status conceptualisations of policy influence. This competitive environment frames research utilisation, offering limited opportunities for all researchers, let alone those who take a socially critical stance. Yet there are good reasons why researchers committed to social ideals such as inclusion, participation and equality may want to pursue opportunities for policy influence and explore contexts where they can see their research may be useful. Griffiths' (2000) theorisation of collaboration and partnership in policy and practice provides three good reasons why critical researchers would want to move beyond the limits of the university and act in tandem with others in the public sphere: 1) on epistemological grounds because knowledge produced from a diversity of opinions is better knowledge; 2) on ethical grounds because knowledge produced with people is more moral than knowledge produced about or for people without their participation; and 3) on practical grounds because involving research users in the research process is likely to enhance its utility. On any one of these grounds it is easy to see why the desire to put our work to use is strong, and even when aware of the challenges critical researchers continue to seek opportunities through public engagement to influence policy and its enactment.

In this article we start from the premise that policy influence for critical researchers requires more careful conceptualisation of the sphere in which we propose to work. The sphere that dominates interactions between research and policy is a public sphere regulated by a neo-liberal state and social policy saturated with market values of competition (Lubienski, 2006), contractualism (Yeatman, 2002) and accountability (Olssen and Peters, 2005). In this sphere, critical researchers struggle to secure a legitimate position beyond that of critic. While the role of critic is important for highlighting inevitable inequalities in a competitive society, it is not wholly satisfying given that our research means we hold knowledge that could address inequalities. Through the deliberation and analysis of our own attempts to act upon policy, through this article we arrive at a position that resists both conceptualising the public sphere where we engage with others as unitary and allowing the public roles we adopt to become defined solely by the relations of a restricted public sphere. In the initial part of the article we draw upon the theorisation of the public, generally, and public engagement, specifically, to theorise public spheres as multiple, differentiated and sometimes emergent spaces of public participation (Mahony and Stephansen, 2017). Within these spheres there are differences in the nature and quality of the engagements between participants and the principles that guide engagement. In public spheres where democracy is strong there are opportunities for policy influence, with ideas spreading through the democratic processes of collective opinion formation and decision-making amongst diverse participants (Fraser, 1990). In the latter part of the article we apply refined conceptualisations of publics and public engagement to our experience of a project that synthesised 
educational research to develop policy recommendations for supporting equality for children and young people.

The Respecting Children and Young People (RC\&YP) project drew upon British research on equality in education from the last 40 years and the expertise of a wide spectrum of researchers, and culminated in the publication and launch of an evidence-based policy manifesto. This was a lengthy and complex project conceived in September 2013 and realised in March 2015, and involved hundreds of educational researchers and others with an interest in education in many different activities. The project was very successful in engaging educational researchers and encouraging them to work together in ways they had not done before, and had some although more limited success in engaging audiences from beyond the academic community through our use of social media, particularly our blog, and the manifesto launch event. While the RC\&YP project has concluded, the application of our new understandings of publics and their engagement to the procedures and outcomes of this project is helping us to develop a methodology for public engagement that can inform other situations and projects.

\section{Public spheres beyond the restrictions of the neo-liberal state}

Public sphere theory conceptually disentangles the state and its apparatuses such as parliament and judiciary from the public sphere (Fraser, 1990; Habermas, [1962] 1991). The public sphere is an arena of deliberation and debate that is associated with political authority, and within a democracy this association is what enables the public to influence political decisionmaking. Public participation in deliberative opinion formation and decision-making within the public sphere should inform democratic government policy. The will of the people should be represented in parliament and inform its debate and decision-making. Indeed, within a democratic government one might consider parliament as an institutionalised public sphere. Yet distinguishing between public sphere and state means recognising that state policy may potentially operate irrespective of the public will and in accordance with priorities different from those in the public interest. Or recognising that an outcome of neoliberal public policy and legislation may be that the public will is shaped by the limited capacity of its public to participate in public processes (Davies and Chong, 2016; Reeves and Loopstra, 2017). In either case, the public sphere is impoverished and its utility curtailed. Certainly, there is extensive evidence that even governments originally founded on democratic political principles give priority in contemporary times to private or commercial interests when constructing social and educational policy, which reflects the change in values from democracy to neo-liberalism (Olssen et al., 2004; Spohrer et al., 2017; Wilkins, 2012).

The consequences of a neo-liberal state are paradoxical for educational research. On the one hand, educational research is potentially valuable in evidence-based policy movements; on the other, the value is set by the priorities of policy demand not research integrity. Demand is based upon the utility of the research as a marker of cultural status or where it sits within a competitive research market. Mangez and Hilgers (2012) argue that in postindustrial society intellectual work, like other forms of cultural work, is now subordinate to economic and political interests, and the value of research is dependent upon production and consumption values. They use the example of the Programme for International Student Assessment (PISA) as a high-status form of knowledge production that draws on an 
extensive set of accumulated economic, cultural and symbolic resources, yet is orientated towards its consumption.

Thus, to the external observer, PISA seems to function as a rather malleable product - i.e. one that can help achieve different purposes, support different arguments and hence be found useful by different kinds of actors occupying different positions within policy fields and in the field of power. (Mangez and Hilgers, 2012: 201)

Critical research is not necessarily without value in this environment, especially when its production value is drawn from high-status forms of critical knowledge and resources (for example, when it is produced within elite universities or draws from a patriarchal and Eurocentric canon), but its value then is not based on its capacity to inform social change and its potential for doing so is limited. Even if it is taken up within the policy field, it is likely to be co-opted by interests that remove it from its socially critical intent.

This sounds very pessimistic for critical researchers attempting to work at the policy/ research interface, yet the distinction between the neo-liberal state and the public sphere offers us room for manoeuvre and some optimism on two fronts that we explore in the next section of this article. First, critical researchers can exploit and draw upon the elasticity and multiplicity in contemporary conceptualisations of the public sphere (Fraser, 1990; Mahony and Stephansen, 2017). Pluralism in the public sphere arises from recognition that the foundational elements of democracy, such as deliberation, opinion formation and decision-making, have not been evenly distributed throughout populations. Groups have been excluded from participation in the public sphere through typical social divisions such as ethnicity, culture, gender, dis/ability or age. Fraser (1990) critiques the patriarchal public described by Habermas, and proposes we reconceptualise the public sphere as multiple spaces where different discourses circulate. Fraser uses the example of feminism, which she argues arose as a strong counter-public sphere that took its discourse of critique into the mainstream public where its influence extended to wider public policy. We see significance in this concept for the work of critical researchers because it offers the opportunity to work outside of the mainstream policy sphere that we have difficulty accessing, and find alternative spaces that may be more receptive to our messages.

Second, public spheres are sites of participation and engagement, and provide opportunities for changes to the framing and enactment of regulatory discourses or disciplinary practices. Ball and Bowe (1992), in discussing policy as a cyclical process rather than a tangible entity, differentiate between intended policies, actual policies and policies-in-use. Policies-in-use are defined by Ball and Bowe (1992) as the following:

...institutional practices and discourses that emerge out of the responses of practitioners to both the intended and actual policies of their arena, the peculiarities and particularities of their context and the perceptions of the intended and actual policies of other arenas. (p.100)

The gap between intended, actual and policy-in-use is a space in which we interpret discourses, and processes of interpretation and translation offer the possibility for practices of resistance such as subterfuge, superficial adoption or reappropriation.

Braun et al. (2011) highlight the complexity and variation of contextual influences on policy, which can overtly or subtly shape interpretations and enactments of policy. Drawing on Bernstein's notion of recontexualisation, Singh et al. (2013) identify mid-level policy 
actors who play roles in reframing the contexts of policy, and others in this special issue propose strategies for critical researchers to mobilise their knowledge in reference to the work of policy intermediaries. Together these ideas give us hope of making use of entry points into the mainstream public sphere such as working with lobbyists or policy advocates whose positions are closer to our own to intervene in policy discourses, or through our educative roles reframe the discourses that shape professional practice.

\section{Pluralism in public participation}

In critical education research the modern state tends to be thought of in relation to its regulatory rather than participatory practices. Pluralist conceptualisations of the public sphere provide a more complex picture. While public participation tends to be associated with collectivist ideologies, there are many examples in the policies of modern neo-liberal or 'third way' governments increasing the range of actors participating in policymaking and its enactment. Government services of the early 21 st century, for example, have shifted immensely towards taking more seriously the publics who use them. Yeatman's (2002) work on contractualism identified the shift of public services away from a model of the professional as expert to include service users in decisions that affect them. This shift has been long recognised as anything but straightforward. For example, Arnstein's (1969) theoretical work on power structures and citizen participation questions the extent to which attempts to redistribute power truly enable the 'have-not' citizens (i.e. those who are excluded from political and economic processes) to be deliberately included. Arnstein argues that where participative acts are restricted to tokenism, "there is no follow-through, no "muscle", hence no assurance of changing the status quo' (p.218).

More recently, Newman et al. (2004) set out how a growing emphasis on public participation in policy discourses can be 'situated in conceptions of governance that result from the transformation of modern states' (p.203). Here they are referring to the role of the state shifting from 'governing' through direct forms of control (hierarchical governance), to that of 'governance', where the state must work with a wide range of individuals, groups and organisations. Indeed, they draw on public administration and social policy research to describe the ways in which governments 'have attempted to shift the focus towards various forms of co-production with other agencies and with citizens themselves through partnerships, community involvement and strategies of "responsibilisation" (p.204). Arnstein might question whether this shift has genuinely resulted in what he terms 'citizen power' or whether 'illusory forms of participation' and co-production are more likely taking place, where public participation is distorted into 'a public relations vehicle by powerholders' (pp.220-221). Yet, Newman's analysis engenders possibilities for equality and participation that we cannot disregard. We recognise and advocate for understanding and calling out the restrictions placed upon the participation of citizens, but believe that participation, even in its restricted forms, can be understood also as an expression of opposition to competitive and hierarchical social organisation and desire for more mutually beneficial relations. Furthermore, we are interested in the spheres of participation that exist outside of, yet interact with, formal relations between citizens and government, especially when they are differently organised from the mainstream public sphere.

A significant problem with participation in the neo-liberal state is that service users have been conceived as consumers with individual needs who enter into contracts with service providers, rather than representatives of collective need who are entered into a social 
contract. Participation is regulated by 'responsibilisation' or the '...self-management of risk by the autonomous individual...' (Liebenberg et al., 2015: 1008) and puts the burden of responsibility for decision-making upon individuals, without due consideration of their capacity to make decisions. This is a serious concern when viewed in the light of contemporary currents of populism, where we are seeing individuals contributing to a political will that works in opposition to the public interest. For example, the 'Brexit' vote to leave the European Union (EU) will have negative consequences for deprived areas in England and Wales due to their loss of future EU funding that is unlikely to be compensated by a financially struggling national purse (Rhys, 2017; Sharman, 2017). In this context, advice from critical researchers to increase funding to impoverished communities is unlikely to gain traction with policymakers.

Yet, alongside the contract between individual members of 'the public' and the state sit other publics that organise themselves around different sets of principles, and at times interact with the public participation processes of state. There is scope for decisions made in counter-publics to influence those made in mainstream public policy. The restrictions of both contemporary state policy and market relations in education work against the formation of counter-publics (Boyask, 2015), yet some recent examples exist. For instance, in England there has been a significant upswell of criticism of primary school assessment, resulting in a coalition of parents, teachers, early childhood practitioners, academics, psychotherapists and other lobby groups forming under the banner of the More Than a Score Campaign. The coalition is campaigning for change to assessment policy, recommending an assessment alternative to national standardised testing that '...treats young people in the round as whole persons...' and '... enables a dialogue between parents and teachers' (More than a Score, 2017). Following continued action by the different lobby groups within the coalition and other critics acting independently, the government launched a consultation on five key proposals for primary assessment, that include the scrapping of key stage 1 SATs and suggest a change of direction in government policy (Greening, 2017).

\section{Public engagement in research}

Just as we have seen attempts by the state to shift paradigms of public engagement in relation to how information is shared and how goals and policies are set, there are similar changes in relations between researchers and publics. Wilsdon and Willis (2004) describe a model of public engagement in research that is premised on dialogue, defined as two-way and bottom-up forms of interaction, between scientists/researchers and public communities. This appears to echo Arnstein's desire for processes of participation to move from those of non-participation ('manipulation' and 'therapy') and tokenism ('informing', 'consultation', 'placation') to forms of engagement that are more based on 'partnership' (shared planning and decision-making), 'delegated power' and 'citizen control'. Furthermore, Watermeyer (2011) presents the current drive to encourage UK researchers 'to do public engagement work' (p.386) as a consequence of events and changes in science governance which began in the mid-1980s. He sets out how the approach to the Public Understanding of Science, which was established in the Bodmer report (Royal Society, 1985), was "informed by a "deficit" rationale that segregates the expert from the public by a respective abundance and paucity of knowledge capital...' (p.386).

The public engagement agenda for UK higher education, as led by the Research Councils UK, has, however, attempted to move away from the Bodmer report definition to one that 
draws comprehensively on Wilsdon and Willis's (2004) 'upstream model' of Public Understanding of Science. Watermeyer (2011) points out that a network of Beacons for Public Engagement are charged with 'promoting, facilitating and embedding public engagement in UK HEIs premised on a model of dialogical interplay between non-expert public groups and academic experts across all subject disciplines' (p.388). Indeed, Watermeyer (2011) suggests that 'the Beacon vision is of university experts sharing with and learning from non-expert public groups and in so doing building more cohesive, confident and fluent academic-public knowledge partnerships' (p.388).

While the dialogic Beacon vison is closer to the kind of public engagement we want to engender since it involves reciprocity and participation, compared with our experience the Beacon vision is attractive, but unrealistic. Partnerships in their ideal form are based upon equality, but as critical researchers are acutely aware, equality in social relationships is rare. Many of us are not recognised for our expertise within the policy sphere where we seek influence, and, therefore, any form of relationship is difficult to establish. Neither are all partnerships considered equal. The partnerships researchers form may not be recognised within the UK higher education accountability frameworks, or at least have not become embedded within its practices. Lord Stern's independent review (2016) of REF2014 suggested that universities were limited in proving impact by the requirement for submissions to track back from measurable research impact to an identifiable research output. Furthermore, universities had been conservative and narrow in their interpretation of impact in their submitted case studies, and thus had not included all they might. This leaves critical researchers in a situation of inevitable and unenviable tension between being held to account for research impact on the one hand, yet lacking knowledge, resources and recognition for public engagement that 'counts' on the other.

In the remainder of the article, we reflect upon what carefully considered public engagement might look like through analysing our experience on the RC\&YP project. This analysis builds upon our contention that a more refined understanding of 'public' can help clarify what critical research can and cannot achieve through public engagement. After describing the project and its outcomes, we draw upon Mahony and Stephansen's (2017) analytical framework that differentiates the conceptual bases of different forms of 'public' in public engagement.

\section{Public engagement in the context of the RC\&YP project}

As briefly suggested in the previous section, we both took an influential role in the RC\&YP project. At the time of its conception, we were co-convenors of the British Educational Research Association's Social Justice special interest group (SIG), which worked on the project with five other SIGs ${ }^{1}$ that shared interests in equality. Ruth Boyask (first author) assumed leadership of the whole project and was supported in this role by eight representatives from the six SIGs involved, including Katy Vigurs (second author). We worked together on co-ordinating the Social Justice SIG's contribution to the project. As might be expected from a group committed to social justice, the project aspired to be inclusive and encourage wide participation in its processes and outcomes. This initially extended to how the SIG convenors engaged educational researchers in the project and latterly to the issue of wider public engagement through the project's blog and other social media sites (such as Twitter and LinkedIn). Project leader Ruth Boyask took advice from senior colleagues from within the British Education Research Association (BERA) in a variety of areas, such as 
how to engage other researchers, how to synthesise research for policy and how to talk on issues of policy on behalf of the many interests represented within the project. In terms of involvement of the Social Justice SIG and its membership, the group's convenors took a staged approach. We first identified members who had published research that aligned closely with the aims of the project; and directly contacted 31 educational researchers with invitations to contribute a guest blog post. On the back of this request, we were able to publish 19 research-based blog posts from SIG members in the four months between June 2014 and the BERA annual conference in September 2014.

We ran a pre-conference project workshop the day before the conference opened. All members of the Social Justice SIG were invited to this event to develop and shape the SIG's contribution to the planned education policy manifesto through working with the pieces of research-based writing posted on the blog thus far, and use these to identify key points and develop a structure onto which we could hang them. This event was attended by 20 members of the SIG (10 blog authors and 10 regular members), and at this event we developed the basic structure for the Fair and Equal Education manifesto. In October 2014 a separate event was held which brought together members from all six participating SIGs to work on developing the content of the manifesto. The SIGs worked within their own groups in the morning and then in thematic cross-groups in the afternoon.

Thereafter, all BERA members were invited to submit blog posts based on their past or ongoing research. This led to a further 13 research-based blog posts being published by Social Justice SIG members between October 2014 and March 2015. If members did not want to write their own blog post, they were encouraged to sign up to follow the blog, to read the posts and to consider commenting upon published posts from their perspectives in order to stimulate public debate and dialogue. There were 24 comments on Social Justice SIG posts. In terms of wider public engagement, each Social Justice blog post was formally promoted and publicised by the convenors via professional and academic networks on Twitter and LinkedIn. Many of these posts were then further promoted by others using social media (who were not necessarily Social Justice SIG members or even BERA members), for example via 'retweets' or public 'shares'. By September 2015 posts from the Social Justice SIG had 1192 interactions through Twitter, 694 through Facebook and 195 through LinkedIn. Since its launch in June 2014, the BERA RC\&YP blog has been viewed almost 49,000 times by an international audience. It reached out to related communities and interested others as evident by its inclusion in the metablog, Echo Chamber Uncut, that claims to include feeds from all the education blogs in the UK, and postings on the blogs of other groups and networks such as the RSA's Inequality and Education Network, the network of researchers Reclaiming Schools and the In Defence of Youth Work collective. Meanwhile, the manifesto was constructed through an iterative process that synthesised contributions from all six SIGs that had been made through blog posts and meeting attendance, and was refined and revised by lead editor Boyask (2015) working with Vini Lander and Pam Alldred, and copy-editor Sharon Walker. After peer review and approval from BERA Council, the manifesto was published and we held a launch event with 103 registered delegates on 10 March 2015. At the launch we had five people give verbal responses to the manifesto. They represented different national organisations and interests including the Runnymede Trust, Citizenship Foundation and National Union of Teachers. Boyask took the project to other venues, including a post on academic news site The Conversation and a presentation at the first \#WomenEd conference. The project also sought direct engagement with politicians, although our approaches had a much more limited impact. There were Twitter 
interactions with two Green Party spokespeople for education and a sitting Liberal Democrat MP. We received two direct responses to the manifesto from Liberal Democrat and Green Party candidates. Copies of the manifesto were handed directly to Sir Andrew Carter to distribute to Education Secretary of State Nicky Morgan, and influential opposition and coalition politicians. Katy Vigurs handed a copy directly to Tristram Hunt, opposition spokesperson on education, at an event at Staffordshire University.

Where we are more confident of our success is in influencing the educational researchers of BERA. Through the RC\&YP project we engaged education researchers and got them working together for a larger purpose. We worked across six SIGs in a way that was described by the President of BERA Ian Menter as an ambitious project that had not been attempted before; while these groupings had a commitment to equality in common they were also methodologically and substantively diverse in their interests. Within the social justice SIG we also brought researchers with a diversity of interests to work together, including researchers from very different points in their careers from early career researchers to esteemed professors. We also drew in researchers from outside the SIG and the UK through a special issue of the BERA newsletter, Research Intelligence, that focussed upon 'Respecting Children as a Global Issue' and a symposium at the American Educational Reseach Association annual meeting in Chicago.

The project guided all these people to step aside from critique and analysis to develop clear statements of policy with the aim of providing hope for an uncertain future, and we have the evidence of this success in our blog and the published manifesto. We have also been influential within BERA itself and our blog influenced the development of a new BERA blog. We have been invited to talk about public engagement and policy influence to other educational researchers at other universities and conferences. The researchers we engaged told us they valued the opportunity to come together to discuss and reflect upon the big and important issues of our field, in a way uncommon to their current working practice. Yet, in reflecting upon this project we are aware that many decisions we made were intuitive, and, when measured by the normative terms that frame research quality, our impact was limited. For example, it is unlikely that this project would have been included as an impact case study in REF2014. The most significant impact was upon the educational research community. While the Stern review (2016) reminded us that impact includes public engagement and recommends recognition of academic impact, in the proposals for the next REF (HEFCE, 2016) educational researchers do not constitute a public and academic impact is limited to academic advances within the discipline. We believe that a refined understanding of publics not only helps to reveal the significance of our work and its success in public engagement, but also helps focus our attention on the publics where we are more likely to have success with engagement and also consider whether they offer more opportunity for official recognition of impact.

\section{A typology of publics in the RC\&YP project}

Writing on the meanings of 'public' in public engagement with research, Mahony and Stephansen (2017) present a framework that clarifies for researchers three distinct ways of conceptualising 'the public' that they regard are 'differently useful' (p.40). They claim that, most commonly, the public referred to in public engagement is conceptualised as a bounded entity that exists independently of its engagement with the research. This is a concrete, real group of people, who can be defined, tracked and measured using calculative processes. In the case of our attempts at public engagement in the RC\&YP project we had conceptualised 
children and young people, separated by age from adults in social and educational policy, and members of parliament with an interest in this policy as two bounded entities with major stakes in our project, yet no participation. This conceptualisation of public also assumes that '...public engagement is an activity that will somehow reach out to, work on behalf of, or communicate with an entity that is already there' (Mahony and Stephansen, 2017: 39). Mahony and Stephansen associate this concept of the public with a positivist epistemology, arguing it has strategic significance for researchers in that engaging with a bounded public can more easily satisfy demands for researcher accountability. We can see that researchers' engagement with bounded publics would be easy to account for as impact; in REF2014 '....impact is defined as an effect on, change or benefit to the economy, society, culture, public policy or services, health, the environment or quality of life, beyond academia' (REF2014, 2011, p.48). Effects, changes or benefits are relatively easy to gauge through calculative methods on a defined group.

Taking into consideration Griffiths' (2000) arguments that knowledge co-constructed is better and more ethical knowledge than knowledge applied to or constructed about a group of people, we question the moral basis of conceptualising public engagement as the exchange of knowledge from researcher to a pre-existing entity. We also wonder about its efficacy for critical research. In respect of our own project, while it may have been desirable to use our manifesto to talk directly to the potential audience of our work (politicians) and influence their decision-making, there was a considerable gap between our message and the message this audience wanted to hear. For example, one of our policy recommendations derived from educational research was to reverse private involvement in public education. The Westminster governments from 1999 onwards (Labour, Conservative-Liberal Democrat Coalition and Conservative) have incrementally worked towards the privatisation of the education system. We were starting from a position of disadvantage.

A second conceptualisation of the public, which Mahony and Stephansen (2017) term as normative, defines a public according to a pre-existing ideal of what a public could or should be. This conceptualisation of public is more compatible with research that takes a moral position, or in our case a socially critical standpoint. The processes we adopted in the RC\&YP project were consciously democratic and fostered open debate within deliberately structured situations. We brought together groups of educational researchers who had not necessarily worked together before, but we identified as having the capacity to bring knowledge, debate and give guidance to our project. At the end of the project we were beginning to extend out these processes to a wider group of participants, and our manifesto launch invited speakers and an audience from organisations and networks who we perceived had similar aspirations to our own. Yet, the extension of the project to a wider group of participants proved challenging. Mahony and Stephansen (2017) relate a normative view of public to the critical theory of Habermas ([1962] 1991), where a deliberative democratic public is defined through the rules of an ideal speech situation - an ideal form of engagement that can never be attained but acts as a regulatory framework for actual engagement. They also relate the concept of the normative public to theories that critique idealism. They include Fraser's (1990) notion of pluralist subaltern or counter-publics where strong forms of democracy outside of mainstream public spheres may flourish and circulate counter discourses, or Laclau and Mouffe's (1985) radical democracy that conceives of the public sphere as agonistic and constitutive of the identities of publics, not through comparison with ideals but through exertion of power (Mouffe, 1999). Mahony and Stephansen (2017) suggest that a normative conceptualisation of public engagement is limited, like the bounded 
public, because ideals exist outside of the practices of engagement. There are fears that a researcher's perspective coloured by ideology lacks objectivity.

And finally, Mahony and Stephansen (2017) conceptualise a third form of public that they associate with a critical and reflexive view of publics. This is a view of publics as emergence orientated, that is, formed and transformed through collective activities, interrelationships between participants or through the circulation of discourses. Warner (2002) argues that this type of public is self-organising, emerging through an audience's engagement with social and material texts. Within the context of the RC\&YP project, this type of public may have emerged through our use of social media that included a project blog with posts from educational researchers and some others who contributed to our project, and the use of Twitter to promote them and other milestones in our project. The posts on Twitter in particular fostered new connections between Twitter users and the project and its activities, resulting in conversations we would not have had otherwise, and allowed us to contribute to pre-existing conversations. This conceptualisation of publics in public engagement presents some optimism for critical research, since it offers scope for publics to form around emancipatory discourses. 'Emergence-oriented perspectives are discernible within the growing literature on co-production and participatory research that emphasizes the need to decentre the authority of researchers and empower the researched' (Mahony and Stephansen, 2017: 40). Yet Warner (2002) talks about such publics being unknowable, organised independent of institutional frameworks and self-created. They exist as a circularity, created by discourse while participating in the production of discourse. In our view, this circularity limits opportunities for engagement with critical research because an emergent public lacks a compass that directs it towards discourses of emancipation over and above discourses of oppression. While some emergent publics are spaces very open to critical researchers, others may be very hostile.

\section{Critical discussion}

Viewing the RC\&YP through the first of Mahony and Stephansen's (2017) lenses shows up the limited impact we had upon bounded publics. Embedded within the conceptualisation of the project was the assumption that we could act as intermediaries between the two bounded entities of children and young people on the one hand, and the politicians who legislate for their education and well-being on the other. We drew on the best resources of our field, including the work and involvement of innovative new thinkers, world-renowned educational researchers and connected ourselves with the high-status knowledge of elite universities. Yet, these resources were already diminished within mainstream policy spheres. In the UK, sociology of education generally, and critical sociology of education in particular, came adrift from policy in the 1980s and 1990s as policy took a neo-liberal turn (Shain and Ozga, 2001). In the educational research paradigm wars of this period, critical researchers were accused of pointing out social inequalities but offering few solutions to resolve them. Within these debates and similar ones in other areas of public policy, critical researchers retreated to the position of social critic and stood aside from mainstream policy discourse. While we achieved more through our engagement with other educational researchers, and could evidence changes in their behaviour, there was no recognition for impact on this group within the REF accountability framework. Recognising how critical research is positioned in relation to bounded publics helps explain our limited impact within mainstream policy circles and our more profound influence in spheres where our legitimacy is less open to question. It helps us identify the hurdles we need to overcome to change our level of influence, so we 
may assess if they are too great for the effort we are willing or able to extend, and to pinpoint the counter-publics where we might better employ our efforts at public engagement. It also suggests that in order to change our present position and locus of influence we need to raise our voices within the parts of the academy where we can leverage influence to advocate for changes to higher education research policy.

The other two conceptualisations of publics offer different possibilities for public engagement. Emergence-orientated publics are new configurations; typical examples are the formations emerging through dialogue in the spaces created by new technologies. There has been debate on whether social media platforms such as Twitter or blogs create public spheres since debate and opinion formation is restricted in two senses (Azumah, 2015; Fuchs, 2014). The first are restrictions upon individual freedom, arising through limits to material resources (for example, technologies) or cultural resources (for example, different educational experiences). The second are restrictions to the freedom of association, where large organisations monopolise assembly and drown out critical voices so they become irrelevant and lack influence. We found social media platforms offered a forum for direct engagement that did not depend upon lengthy publication processes or getting past traditional gatekeepers. We set up our blog as a space where educational researchers could speak for themselves, and found ourselves on the edge of the edu-blogging community who were similarly attracted to the apparent open and accessible debate on educational issues afforded by social media. Within these fora, there was an appetite for and interest in educational research and we made some headway in making connections within this sphere. Full integration remained elusive, however, and more powerful statements about educational issues seemed to come from larger groups, such as school teachers, and better-resourced groups that held greater sway in policy circles such as think tanks and policy groups. We also noted criticisms from outside of the educational research community voiced against some of our contributors and the quality of their research, in particular questioning the rigour in critical and qualitative methodologies that had produced knowledge of inequality. The criticisms lobbied against our work came from a very small minority of the audience, but they took on significance when BERA withdrew support for the blog and requested at around the same time some of these criticisms appeared as critical comments on blog posts that we close the blog down on publication of our manifesto. We had conceived the blog as a space for dialogue, yet our capacity to engage productively with politically different views was limited.

In light of our reflections on the RC\&YP project, we think that Mahony and Stephansen's (2017) normative view of publics offers critical researchers the most productive platform for public engagement. Within this conceptualisation of public, we can orientate our work in engagement to our ideological position, meshing our critical understandings with ideologically compatible processes of democracy, inclusion and participation and the publics who support them. Conceiving of 'public engagement' as democratic participation within mainstream and counter-publics opens some space for critical researchers. While we may struggle to attain influence in the mainstream policy sphere, or risk being drowned out by louder or more powerful voices in the emergent public spheres created through apparently neutral technologies, we can find and build alliances with other publics that form around sets of governing principles more compatible with our own.

We interpret our success in mobilising educational researchers, initially with those to whom we were close in ideology, and eventually rippling out within the wider community and beyond as an exercise of public pedagogy. Kenway and Fahey (2011) suggest that public pedagogies help to inform the ways in which people engage and transform both culture and 
politics: '. . .culture (broadly defined) involves public pedagogies, which continually help to mobilise and transform meanings and emotions and help to shape identities, relationships and social, cultural and political divisions and distinctions' (p.167). They refer to Giroux (2004) who argued that public pedagogies also provide a 'sphere for imagining oppositional social change' (p.60). Azumah (2015) suggests that the work of blogs as a form of public pedagogy is successful when they are able to 'listen to what is really going on. Speak the unspoken thoughts and feelings... This is a space the public pedagogue defines and occupies to create the possibilities of alternative educational futures' (p.298). To us, this seems to be moving towards a more authentic way to conceptualise our public engagement rather than attempting to achieve demonstrable policy change or change opposing views from the outset.

We feel we should not be aiming through public engagement to talk to everyone, at least not initially. A more realistic goal is to approach engagement from the rules of democracy, or an idealised public sphere. For example, drawing upon Dewey's (1916/1994) ideas on democracy and education public pedagogy starts with our immediate sphere of influence, working with those around us. An important role for us is educative, promoting the reconstruction of experience '... which adds to the meaning of experience, and which increases ability to direct the course of subsequent experience' (p.74), and through the promotion of educative experiences contribute to the extension of equality throughout relations amongst all members of our social groups and beyond to other unfamiliar groups. Relating these principles to our experience of the RC\&YP project puts into perspective our success within the educational research community. It was within that public sphere where our positions as community organisers (i.e. co-convenors of the Social Justice SIG), relationships of trust and mutuality with colleagues and shared commitment to socially critical ideals enabled us to enact our public pedagogy and reorganise experiences within the SIG. The more difficult task was extending our public pedagogy to external groups, yet we had begun the work through making connections with other groups that held similar social aspirations and interests. In time, these connections may have strengthened into the fluid and reciprocal relationships described by Watermeyer (2011).

\section{Declaration of conflicting interests}

The author(s) declared the following potential conflicts of interest with respect to the research, authorship, and/or publication of this article: Ruth Boyask is an elected member of Council and trustee of the British Educational Research Association.

\section{Funding}

The author(s) received no financial support for the research, authorship, and/or publication of this article.

\section{ORCID iD}

Ruth Boyask (D) 0000-0001-6596-4888.

\section{Note}

1. The other SIGs involved were Race and Ethnicity in Education; Sexualities, Youth and Informal Education; Inclusive Education; and Practitioner Research. 


\section{References}

Arnstein SR (1969) A ladder of citizen participation. Journal of the American Institute of Planners 35(4): 216-224.

Azumah DC (2015) Blogging as public pedagogy: Creating alternative educational futures. International Journal of Lifelong Education 34(3): 284-299.

Ball SJ and Bowe R (1992) Subject departments and the 'implementation' of National Curriculum policy: An overview of the issues. Journal of Curriculum Studies 24(2): 97-115.

Boyask R (2015) The public good in English private school governance. European Educational Research Journal 14(6): 566-581.

Braun A, Ball SJ, Maguire M, et al. (2011) Taking context seriously: Towards explaining policy enactments in the secondary school. Discourse: Studies in the Cultural Politics of Education 32(4): $585-596$.

Davies I and Chong EKM (2016) Current challenges for citizenship education in England. Asian Education and Development Studies 5(1): 20-36.

Dewey J (1916/1994) Democracy and Education. New York: The Macmillan Company.

Fraser N (1990) Rethinking the public sphere: A contribution to the critique of actually existing democracy. Social Text 25/26: 56-80.

Fuchs C (2014) Social Media: A Critical Introduction. Los Angeles, CA: SAGE.

Giroux H (2004) Cultural studies, public pedagogy and the responsibility of intellectuals. Communication and Critical/Cultural Studies 1(1): 59-79.

Greening J (2017) Update on primary assessment in England: Written statement to parliament. Available at: https://www.gov.uk/government/speeches/update-on-primary-assessment-in-england (accessed 28 April 2017).

Griffiths M (2000) Collaboration and partnership in question: Knowledge, politics and practice. Journal of Education Policy 15(4): 383-395.

Habermas J ([1962] 1991) The Structural Transformation of the Public Sphere: An Inquiry into a Category of Bourgeoisie Society. Cambridge, MA: MIT Press.

Higher Education Funding Council for England (HEFCE) (2016) Consultation on the second Research Excellence Framework, HEFCE. Available at: http://www.hefce.ac.uk/media/ HEFCE,2014/Content/Pubs/2016/201636/HEFCE2016_36.pdf (accessed 3 November 2017)

Kenway J and Fahey J (2011) Public pedagogies and global emoscapes. Pedagogies: An International Journal 6(2): 167-179.

Laclau E and Mouffe C (1985) Hegemony and Socialist Strategy: Towards a Radical Democratic Politics. London: Verso.

Liebenberg L, Ungar M and Ikeda J (2015) Neo-liberalism and responsibilisation in the discourse of social service workers. British Journal of Social Work 45(3): 1006-1021.

Lubienski C (2006) School diversification in second-best education markets. Educational Policy 20(2): 323-344.

Mahony N and Stephansen HC (2017) Engaging with the public in public engagement with research. Research for All 1(1): 35-51.

Mangez E and Hilgers M (2012) The field of knowledge and the policy field in education: PISA and the production of knowledge for policy. European Educational Research Journal 11(2): 189-205.

More than a Score (2017) The More Than a Score alternative for primary assessment. Available at: https://morethanascore.co.uk/2017/03/29/the-more-than-a-score-alternative-for-primary-assess ment/ (accessed 28 April 2017).

Mouffe C (1999) Deliberative democracy or agonistic pluralism. Social Research 66(3): 745-758.

Newman J, Barnes M, Sullivan H, et al. (2004) Public participation and collaborative governance. Journal of Social Policy 33(2): 203-223.

Olssen M and Peters MA (2005) Neoliberalism, higher education and the knowledge economy: From the free market to knowledge capitalism. Journal of Education Policy 20(3): 313-345. 
Olssen M, Codd J and O’Neill A-M (2004) Education Policy: Globalization, Citizenship and Democracy. London: Sage.

Reeves A and Loopstra R (2017) 'Set up to fail'? How welfare conditionality undermines citizenship for vulnerable groups. Social Policy and Society 16(2): 327-338.

REF2014 (2011) REF 2014: Assessment framework and guidance on submissions: REF 02.2011. Available at: http://www.ref.ac.uk/media/ref/content/pub/assessmentframeworkandguidanceonsub missions/GOS\%20including\%20addendum.pdf (accessed 7 July 2017).

Rhys S (2017) This is how much money Wales gets from the European Union and how it is spent. Wales Online, 19 March. Available at: http://www.walesonline.co.uk/news/politics/how-muchmoney-wales-gets-12765100 (accessed on 28 April 2017).

Royal Society (1985) The Public Understanding of Science. London: Royal Society.

Shain F and Ozga J (2001) Identity crisis? Problems and issues in the sociology of education. British Journal of Sociology of Education 22(1): 109-120.

Sharman J (2017) Cornwall wanted guarantees it wouldn't lose $£ 60 \mathrm{~m}$ EU funding after Brexit, but the Government turned it down. The Independent, 28 February. Available at: http://www.independent. co.uk/news/uk/politics/cornwall-lose-eu-funding-uk-government-replace-brexit-latest-dclg-requestdown-julian-german-a7603921.html (accessed on 28 April 2017).

Singh P, Thomas S and Harris J (2013) Recontextualising policy discourses: A Bernsteinian perspective on policy interpretation, translation, enactment. Journal of Education Policy 28(4): 465-480.

Spohrer K, Stahl G and Bowers-Brown T (2017) Constituting neoliberal subjects? 'Aspiration' as technology of government in UK policy discourse. Journal of Education Policy, 1-16. doi:10.1080/02680939.2017.1336573

Stern N (2016) Building on Success and Learning from Experience: An Independent Review of the Research Excellence Framework. London: Department for Business, Energy \& Industrial Strategy.

Warner M (2002) Publics and counterpublics. Public Culture 14(1): 49-90.

Watermeyer R (2011) Challenges for university engagement in the UK: Towards a public academe? Higher Education Quarterly 65(4): 386-410.

Wilkins A (2012) Pedagogy of the consumer: The politics of neo-liberal welfare reform. Journal of Pedagogy/Pedagogický casopis 3(2): 161-173.

Wilsdon J and Willis R (2004) See-Through Science: Why Public Engagement Needs to Move Upstream. London: Demos.

Yeatman A (2002) The new contractualism and individualized personhood. Journal of Sociology 38(1): 69-73.

Ruth Boyask's current research focuses upon the changing nature of public education. Public education presently is framed by the legacy of over 30 years of neoliberal policy, and more recent fundamentalisms and populisms that question old forms of legitimacy and the common good. Her research raises and addresses questions about how these changes have impacted upon educational research, policy and practice. She has particular interests in systems of schooling, school governance, educational decision-making and the utilisation of educational research. She has worked in universities in England, Wales and New Zealand, and publishes widely on methodological issues and findings from critically informed empirical research.

Katy Vigurs is an associate professor of Careers and Higher Education in the International Centre for Guidance Studies (iCeGS) at the University of Derby. She publishes on a wide range of educational and methodological issues. She has a particular interest in researching policy and practice relating to inequity and inequalities in higher education. 